\title{
The Major Beliefs and Assumptions of Middle Management about Corporate Effectiveness in the Odl Institution
}

\author{
${ }^{1}$ Daniel Ndudzo, ${ }^{2}$ Robson Jubenkanda \\ ${ }^{1}$ Registrar, Zimbabwe Open University, ${ }^{2}$ Acting Dean, Faculty of Commerce, Zimbabwe Open University
}

\begin{abstract}
This study examines the major beliefs and assumptions of ZOU's middle management on the institution's effectiveness. The broad dimensions to organisational effectiveness identified for this study are the organisational structure, decision making process, resource mobilisation initiatives, motivation, information management and communication. The study seeks to profile middle management's evaluation of the institution regarding the above mentioned dimensions. The research would point to middle management's perception of the direction the institution is heading. The study employed a descriptive survey design. Questionnaires were the main research instrument. The researcher targeted middle managers at the Zimbabwe Open University. The study discovered that ZOU middle management is optimistic that the University is operating effectively, they are confident that the University with its current leadership has the potential to achieve its goals. The major strengths of the institution are its committed leadership, motivated employees, appropriate strategies and plans and its dynamism in responding to market changes. Though the University is on course to achieve its goals, there is need to involve middle management in decision making to enhance implementation of plans and strategies. The effective implementation of the well conceived plans and strategies are being hampered by unavailability of resources. Middle management perceives the current resource mobilization efforts as inadequate. The necessary conditions for organisational effectiveness have been established at the Zimbabwe Open University. To ensure the attainment of the University's goals and to re-assure middle management, it is recommended that the University's senior management establish a platform where middle management actively participate in formulation of strategies, plans and key decision making.
\end{abstract}

\section{Introduction}

The Zimbabwe Open University middle management is composed of Faculty Deans, Regional Directors, National Centre Directors and Managers. Regional Directors are responsible for their respective Regional Centres which are located in the various provinces in Zimbabwe while other Directors, Deans and Managers stationed at the National Centre are responsible for conceiving and implementing Unit level strategies to achieve goals set in the institution's strategic plan. Middle management report to senior management which is composed of the Vice Chancellor, the Pro-Vice Chancellors, Registrar, Finance Director, Director - Library and information Services and Director Information and Communication Technology.

For overall organisational effectiveness, it is imperative that middle management understand the organisational structure, decision making process, resource mobilisation initiatives, motivation, information management, communication and the organisational culture cultivated at senior management level. Coordination and commitment at the two management levels enable the university to effectively implement its strategies and achieve its goals.

Organisational theorists agree that organisational effectiveness is multidimensional (Campbell et al 1974) and there is also reason to believe that the determinants of organisational effectiveness vary (Steers 1977a). For this study the factors that are considered as affecting organisational effectiveness of the Zimbabwe Open University are its organisational structure, resource mobilization initiatives, the decision making process, information management, communication and commitment at all levels.

Scholars of organisational behavior have attempted to establish reliable linkages between organisational performance and employee attitudes, beliefs, assumptions and their behavior, though with mixed results (Vroom 1964). Substantial attention also has been directed towards the importance of attitudes in this relationship (Porter et al, 1974). Attitudes here are said to be built from experience, beliefs and assumptions of employees.

The beliefs, attitudes and assumptions of ZOU middle management on major areas influencing corporate performance have an impact on their overall commitment to the organisation's cause. Commitment as defined by Porter (1974) has three major components which are (1) a strong belief in and acceptance of the organisation's goals, (2) willingness to exert considerable effort on behalf of the organisation and (3) a definite desire to maintain organisational membership. 
This study therefore investigates the beliefs and assumptions of the Zimbabwe Open University middle management on the organisation's effectiveness. It assesses their perceptions on issues raised on several dimensions that are widely believed to affect organizational effectiveness.

\section{Statement of the problem}

Organisational effectiveness depends on the extent to which middle management and senior management cooperate and agree on key issues which include strategies, structure, systems, decisions and information management. No study has been carried out to document and assess the ZOU middle management's beliefs, assumptions and attitudes towards the effectiveness of the current ZOU establishment. The study therefore seeks to answer the following question from middle management's perspective: Is the Zimbabwe Open University operating in an effective way in its endeavor to achieve its goals?

\section{Purpose of the study}

The study aims to examine the major beliefs, assumptions and attitudes of middle management on the organisation's effectiveness. It is hoped that the findings of this study will help in enhancing coordination between senior and middle management for the overall effectiveness of the University. The study also seeks to create a framework with which senior management and middle management can engage to reconcile on areas such as strategy, plans, decision making and implementation. It is hoped that the resultant coordination and cooperation between senior and middle management would enhance the institution's ability to achieve its goals.

\section{Objectives}

The study aims to achieve the following objectives;

1. To assess middle management's perception of the University's decision making procedures

2. To investigate the perceived adequacy of the information \& communication structure of the University in fostering coordination

3. To assess the effectiveness of people management initiatives in the institution from middle management's point of view

4. To assess the effectiveness of the organisational structure

5. To assess the institution's dynamism in responding to environmental changes

\section{Research Questions}

The study will be guided by the following questions.

1. What is the ZOU middle management's perception of the institution's decision making process?

2. Is the information and communications structure effectively creating coordination in the University?

3. Is the institution effectively motivating its workforce?

4. Is the ZOU organisational structure effectively delivering on the institution's goals?

5. Is the institution effectively planning and responding to environmental changes?

\section{Justification of the study}

Effectiveness is an integral element in the achievement of corporate objectives. The institution's overall effectiveness is a function of several factors and functions which interact within the institution. Failure of one department or function of the institution may result in the University not being able to achieve its objectives. It is thus essential for a thorough assessment to be done on the several dimensions that affect effectiveness at the University. Middle management implements the institution's strategies and for them to effectively implement these strategies, they should have confidence in these strategies.

This study assesses the beliefs, views and assumptions of middle management on the University's effectiveness. It is hoped that the findings will present a clear picture of where middle management and senior management agree and where they have contrasting views on factors that have a bearing on the effectiveness of the institution. This would assist in setting a platform for engagement between senior and middle management. Dimensions that affect the University's effectiveness are identified and assessed in this study. It is hoped that lessons would be learnt as to which areas need adjustment and improvement.

Clarity and certainty are critical preconditions for implementing decisions and strategies. It is hoped that this study will reconcile possible areas of contention and misunderstanding between middle and senior management.

\section{Literature review}

Scott et al (2008) defined effectiveness as the likelihood of achieving the intended objectives of an activity, policy or other intervention. Effectiveness is also defined as "the extent to which a development intervention has attained, or is expected to attain, its relevant objectives", Scott et al (2008). Yankey \& 
McClellan (2003) stated that organizational effectiveness is the extent to which an organization has met its stated goals and objectives and how well it performed in the process.

According to Malik et al (2011) factors that may affect organizational effectiveness are: performance in all functions, motivation, organizational environment, managerial expertise, creative synergy and organisational culture.

This study is based on the social constructionist approach to organisational effectiveness.

\subsection{The Social Constructionist Approach to organisational effectiveness}

According to Herman \& Renz (1998), the social constructionist approach views organizational effectiveness as stakeholder judgments formed in an ongoing process of sense making and implicit negotiation. This approach holds that reality is created by the beliefs, knowledge, and actions of people. "Overall organizational effectiveness is whatever multiple constituents or stakeholders judge it to be".

In this approach to organisational effectiveness, people are not expected or required to behave simplistically or rationally. For example, the criteria for assessing organizational effectiveness may change without warning (Kronskosky). Reimann (1975) argued that that the concept of organizational effectiveness is one of the most elusive and controversial concepts in the organization theory literature

The indicators of effectiveness could be interpreted in terms of the accomplishments of goals such as high productivity, morale, conformity and institutionalization. However, most organizations generally are seeking to accomplish several different goals at the same time, and the accomplishment of one of these goals often may inhibit the realization of another.

About effective organization Rethore \& Marian (98) narrated that an effective organization is most likely to have a set of metrics that:

- Holds individuals accountable for their individual performance. This means clarifying individuals' roles, responsibilities, and their authority to make decisions

- Identifies and communicates 'acceptable' levels of risk (and the cost of not managing risk adequately)

- Measures a leader's behavioral impact and how that influences others' performance (or not)

- Clarifies 'what good looks like' since people cannot be effective if they don't understand the (qualitative and quantitative) performance standards

- Identifies the drivers for success to more consistently replicate performance

- Identifies critical feedback loops so that individuals learn and develop confidence in their analysis and decisions

- Challenges everyone to perform at the next level in the organization

Organisational effectiveness from the literature above is said to be synonymous with goal attainment. It is thus important to assess effectiveness in the University by measuring goal attainment at different levels, from individuals, departments, regional centres and the institutional goals.

\section{Methodology}

The study used the quantitative research design. Data gathering was conducted using the questionnaire instrument. Questionnaires were distributed to a sample of 35 middle managers at the Zimbabwe Open University. Respondents were conveniently selected thus questionnaires were distributed basing on availability of respondents. The respondents included Regional Directors, Deans, Departmental Directors and Managers. Respondents were asked to respond to different questions which were mainly evaluating the effectiveness of the University's decision making, information management, structure, motivation and dynamism in response to the needs of the market.

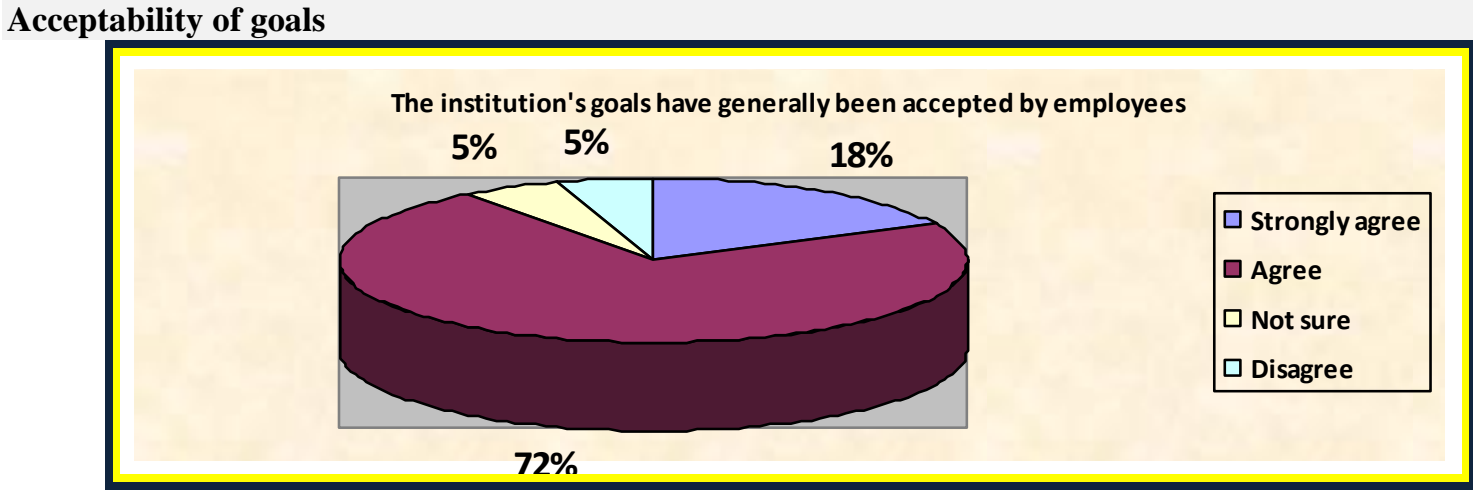


There is a strong belief in, and a general acceptance of, the organisation's goals in the institution as indicated by $90 \%$ of respondents who agreed.

Middle management believes that the University's workforce is committed to achieving the institution's goals. $59 \%$ of respondents agreed that the University workforce were committed to achieving the institution's goals, $18 \%$ strongly agreed while $22 \%$ were not sure.

$68 \%$ of respondents believed that the University was well on course to achieving its goals. $18 \%$ of respondents were not sure, while $14 \%$ disagreed.

From the findings, it can be inferred that the University has set realistic goals which have been accepted in the University. Middle management was well prepared, confident and believed that the institution was well prepared to achieve its objectives.

\section{Plans and strategies}

The findings suggest that the Zimbabwe Open University's action plans and strategies are relevant to addressing the immediate needs, challenges and opportunities faced by the institution. $91 \%$ of respondents expressed confidence in the University's plans.

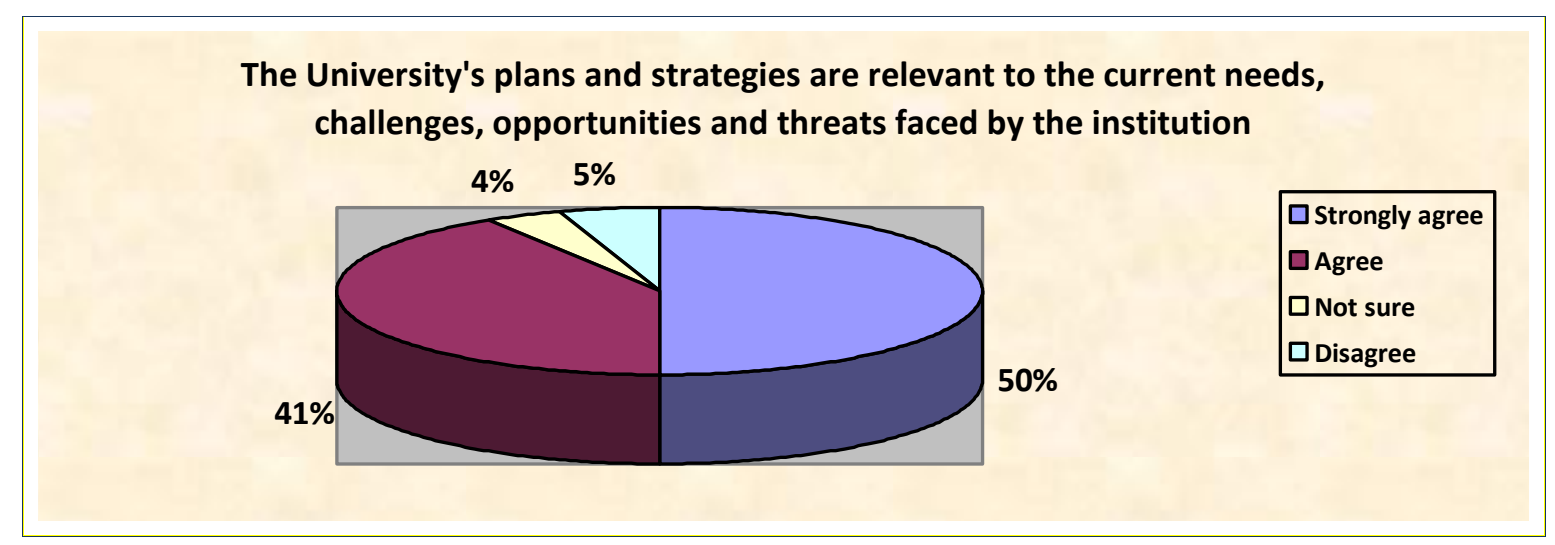

\section{Structure}

When asked whether the University has a "fit for purpose" structure which clearly defines responsibility and accountability, $73 \%$ of respondents agreed while $23 \%$ were either not sure or disagreed with the appropriateness of the structure.

\section{Leadership}

ZOU middle managers believe that the University's leadership has the capacity and capability to drive sustainable business growth. $87 \%$ of respondents agreed that the leadership's had the capacity and capability to lead the institution while $13 \%$ were not sure.

Respondents indicated that there is commitment from leadership to effectively lead the institution in achieving its goals as indicated by $81 \%$ of respondents who agreed that ZOU leadership was committed to achieving the institution's goals. Only $19 \%$ of respondents disagreed.

\section{Resource mobilisation}

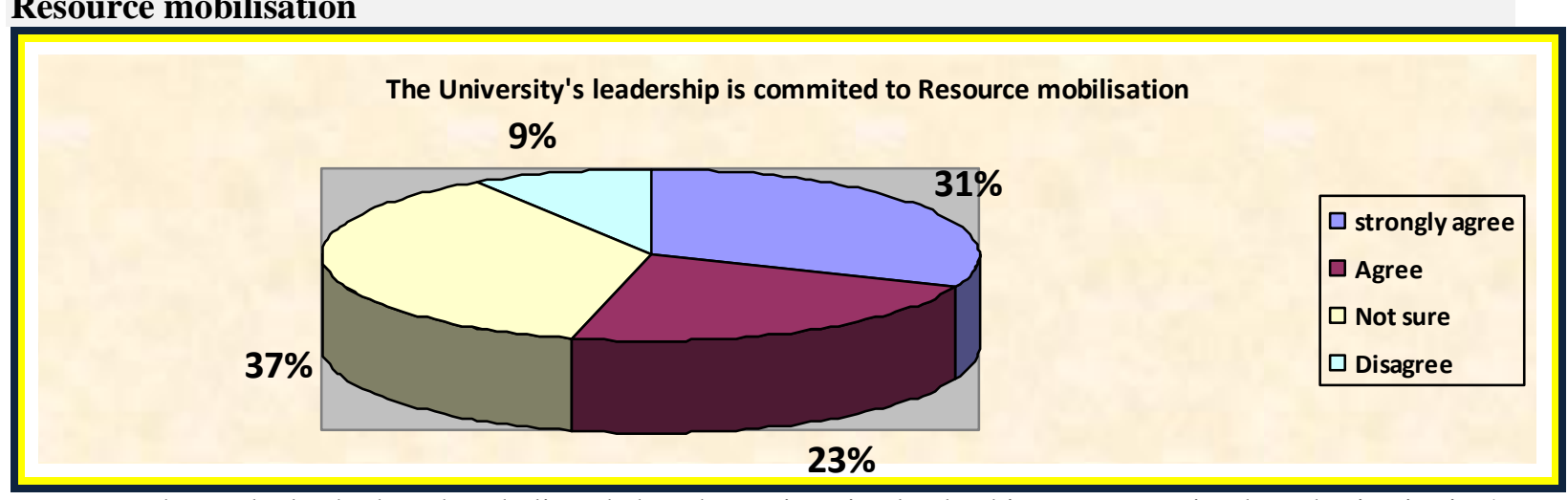

When asked whether they believed that the University leadership was committed to the institution's 
resource mobilization initiatives. Only $54 \%$ of respondents were positive. $46 \%$ of respondents doubted University leadership's commitment towards resource mobilisation.

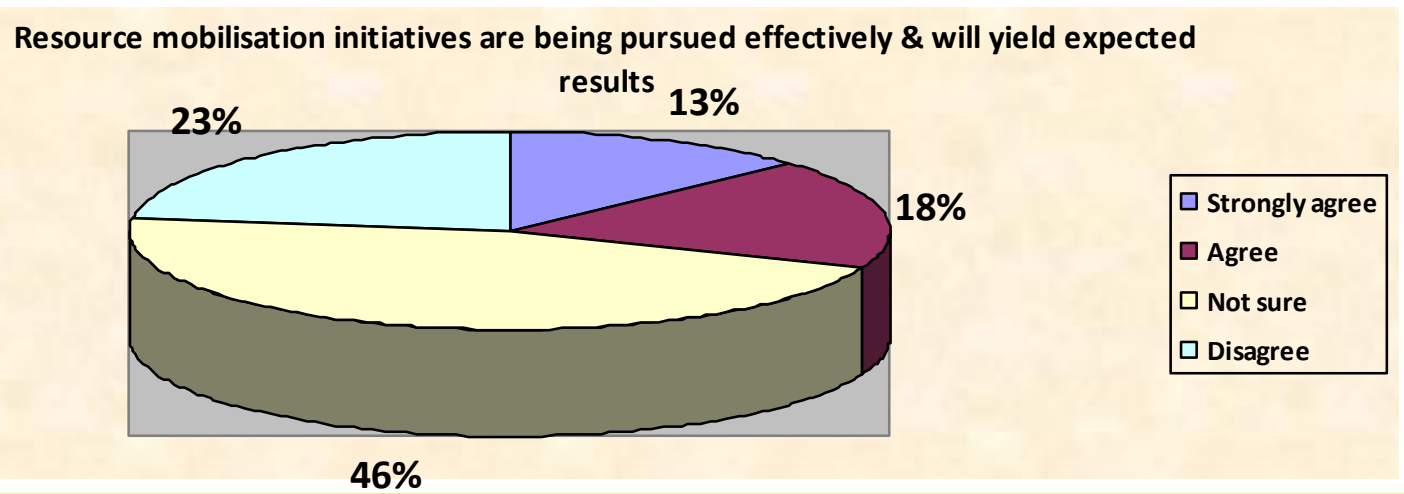

$69 \%$ of respondents were skeptical of the effectiveness of the University's resource mobilisation initiatives. Only $31 \%$ of respondents expressed confidence in the resource mobilization initiatives of the institution.

\section{Work environment}

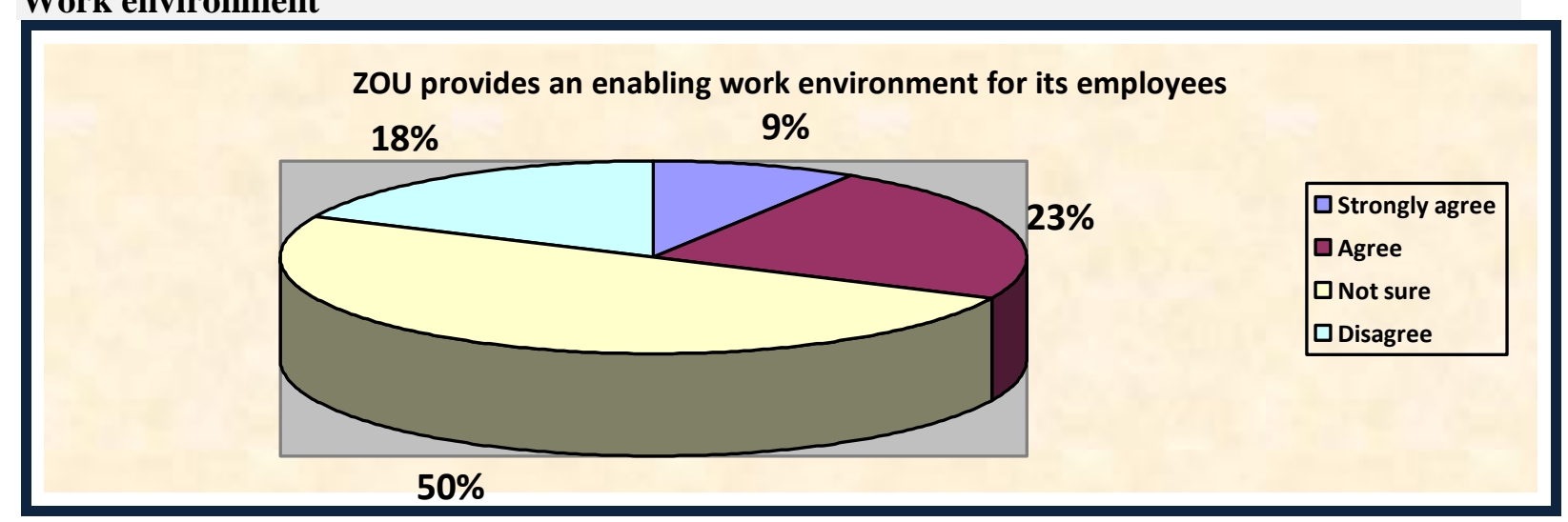

Middle management was overall not very satisfied with the general work environment at the Zimbabwe Open University. Only $32 \%$ of respondents approved of the general work environment.

ZOU middle managers were generally confident of the roles and work design in the institution. $78 \%$ of respondents indicated that the roles and work design at ZOU enhance workforce's ability to contribute to the institution's effectiveness, $8 \%$ were not sure while the other $14 \%$ disagreed and believed that the role and work design at ZOU was improper.

Respondents were of the view that roles are clearly communicated in the institution, this is indicated by $73 \%$ of respondents who agreed that roles were clearly communicated in the institution. $27 \%$ of respondents disagreed.

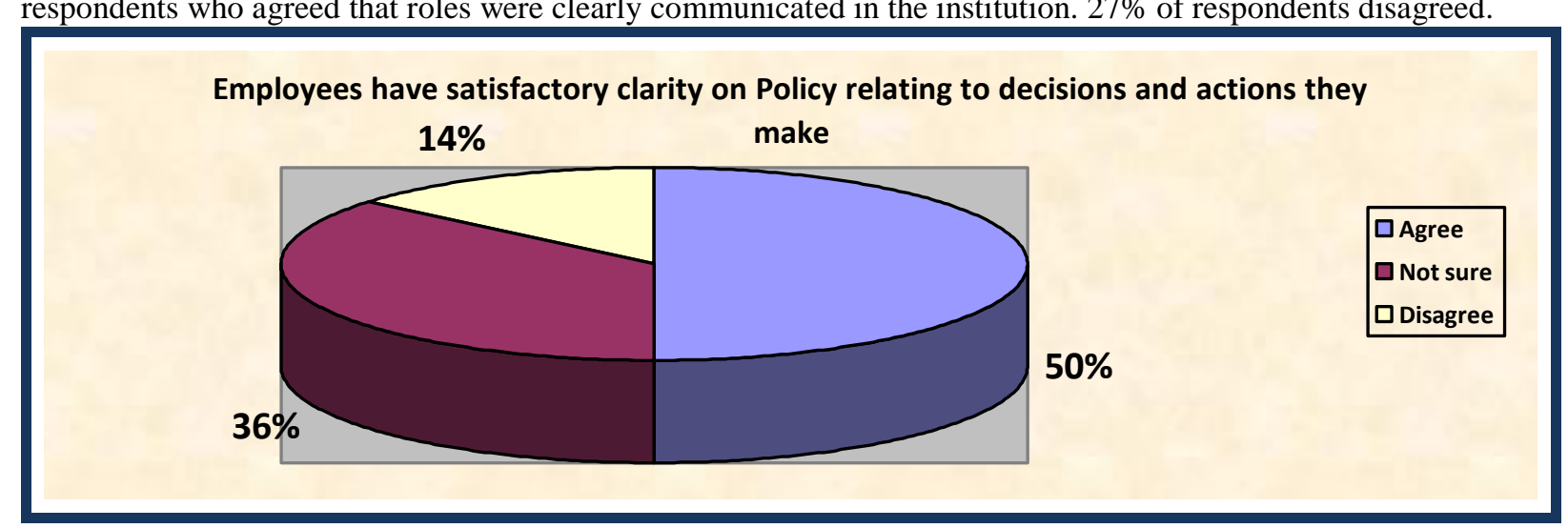


Only half of the respondents $(50 \%)$ were of the view that employees have satisfactory clarity on policy relating to the decisions and actions for which they are responsible. The other $50 \%$ were not confident on the extent to which employees were appraised with Policy issues.

When asked about their views on the adequacy of authority and support given to ZOU employees, only $50 \%$ responded positively. The other $50 \%$ of respondents either disagreed or were not sure whether employees are provided with adequate authority and support to act on customer feedback.

It is thus essential for the University to empower employees with up to date policy documents and clear authority for them to use their discretion in dealing with customer feedback.

\section{Culture \& motivation}

There is no consensus in middle management regarding the nature of the institution's culture as a 'command and control' institution. $36 \%$ of respondents were of the view that the ZOU culture was 'command and control', $32 \%$ were not sure while the other $32 \%$ were in disagreement. It is thus essential for senior management to communicate clearly a culture of inclusiveness down the organisational structure.

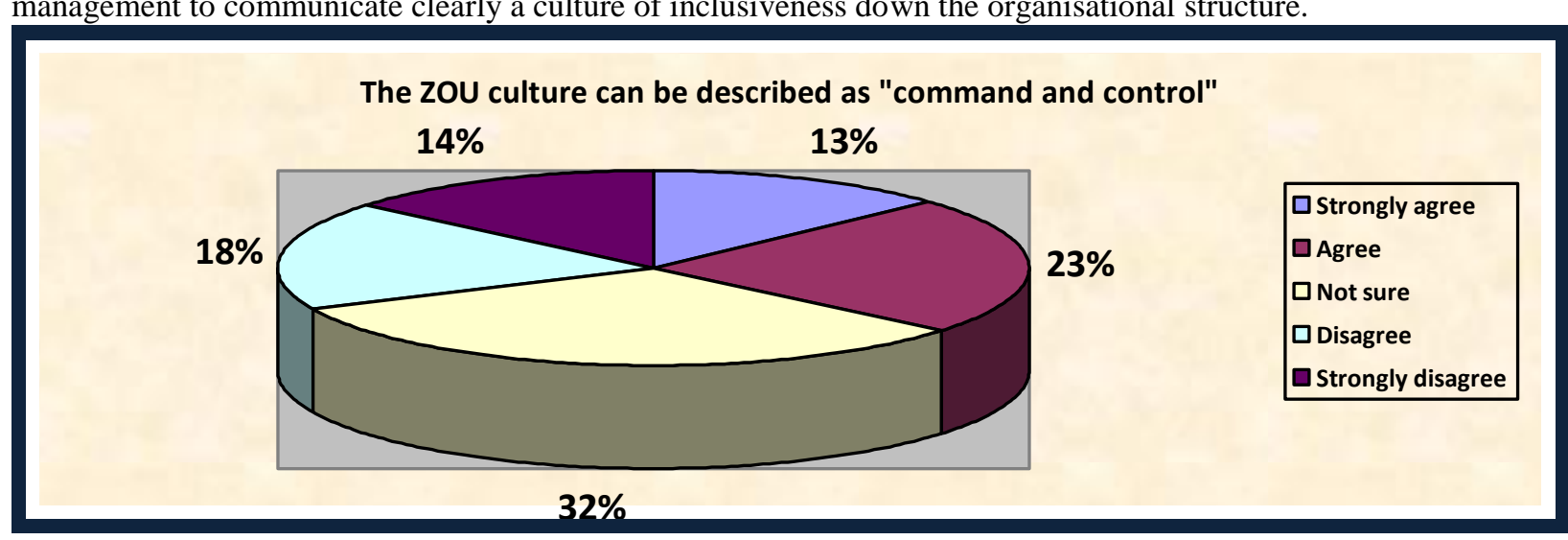

The majority of respondents $(73 \%)$ were of the view that the institution's values are well communicated to employees. Only $27 \%$ of respondents were either not sure or disagreed.

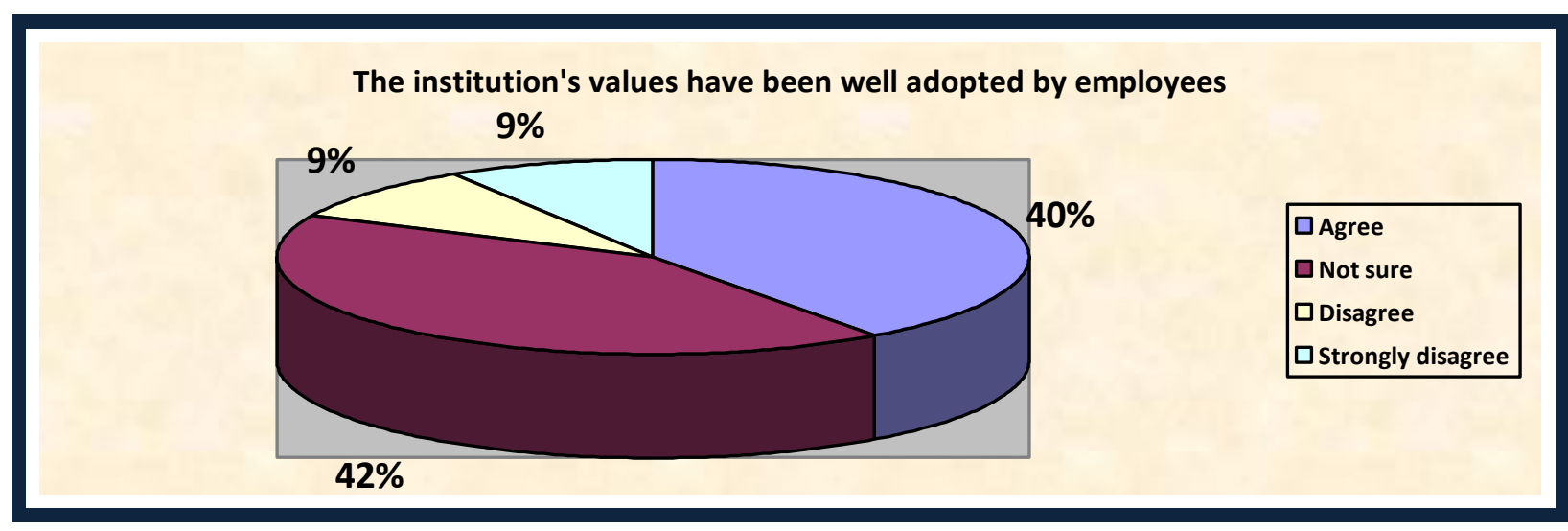

While most respondents believed that the institution's values had been well communicated to employees, the majority are not convinced with the general adoption of values by employees. $51 \%$ indicated that they were not sure whether employees had adopted the institution's values. $49 \%$ of respondents however agreed. 


\section{There is a general feeling of shared purpose and cooperation in the institution}

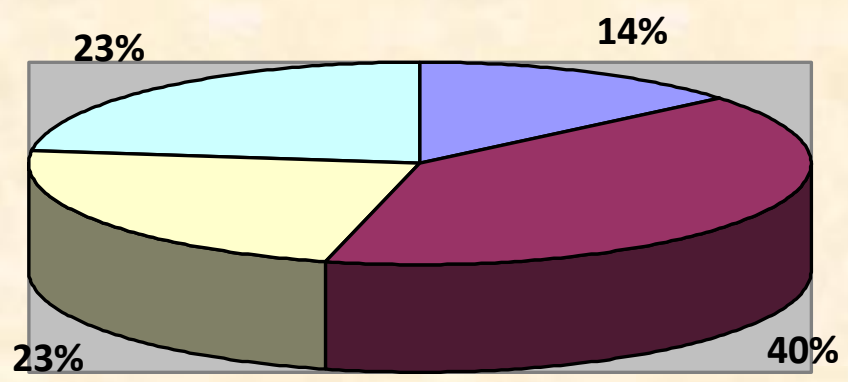

When asked about cooperation and shared purpose in the institution, respondents were of varying opinions. $54 \%$ of respondents agreed that there was a general feeling of shared purpose between university management and employees. $46 \%$ were either not sure or disagreed.

The majority of respondents $(73 \%)$ were of the view that there is a general willingness to exert considerable effort on behalf of the institution. $14 \%$ were not sure while only $13 \%$ disagreed.

Regarding employee tardiness and absenteeism, only $36 \%$ of respondents indicated that there was a general trend of employee tardiness in the University. $64 \%$ were either not sure or disagreed.

It can be inferred from the study that the University has made progress in addressing employee turnover. Only $41 \%$ of respondents agreed that employee turnover was a threat that should be urgently addressed. 59\% of respondents did not view employee turnover as an immediate threat.

\section{Information flow}

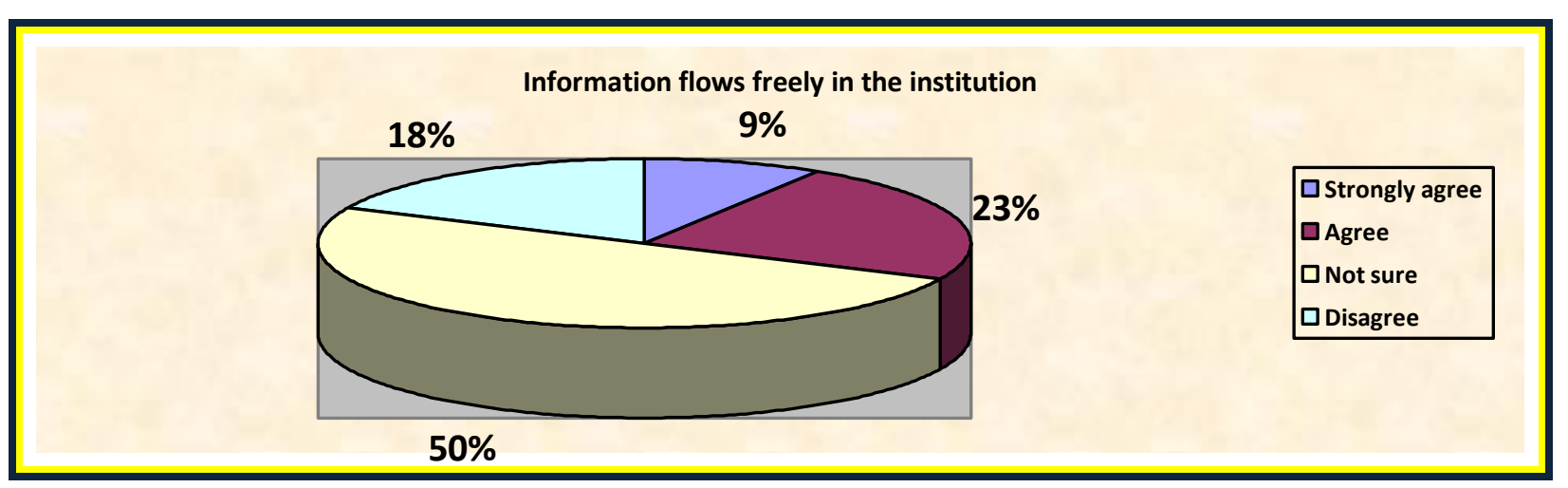

This study revealed that information flow is not effective in the organisation; this is reflected by only $32 \%$ of respondents who agreed that information flows freely in the institution. $68 \%$ of respondents were either not sure or did not agree.

Middle managers were not convinced that the University senior management effectively responds to feedback from middle management. Only $46 \%$ of respondents believed that senior management respond effectively to feedback from middle management while $55 \%$ were either not sure or disagreed with this position. 


\section{Senior management respond effectively to feedback from middle management}

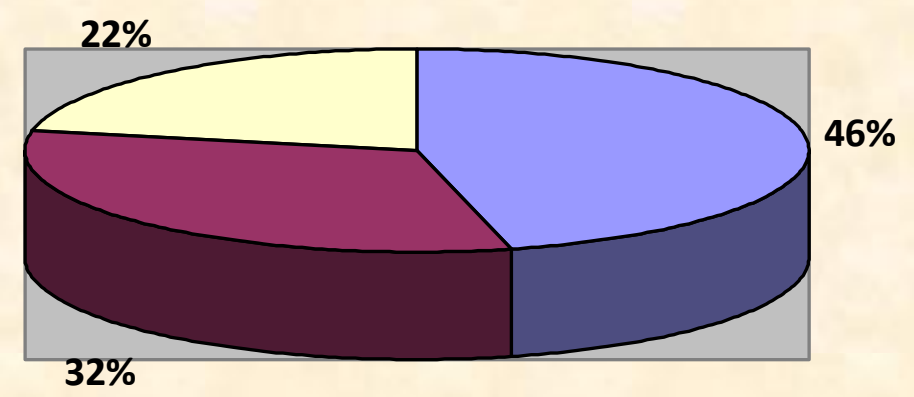

The study revealed that important information about the market and students provided by middle management gets to the National Centre but is not responded to urgently. This is reflected by $68 \%$ of respondents who indicated that such information from middle management was submitted at the National centre but was not responded to with urgency. Only $32 \%$ of respondents were in agreement with this position.

\section{Communication}

Middle managers indicated that communication between ZOU employees in different units is inadequate. 50\% of respondents agreed that the University has adequately connected employees in different units. The other $50 \%$ either disagreed with this position. This therefore calls for measures to improve interdepartmental communication as this has an effect on overall coordination in the institution.

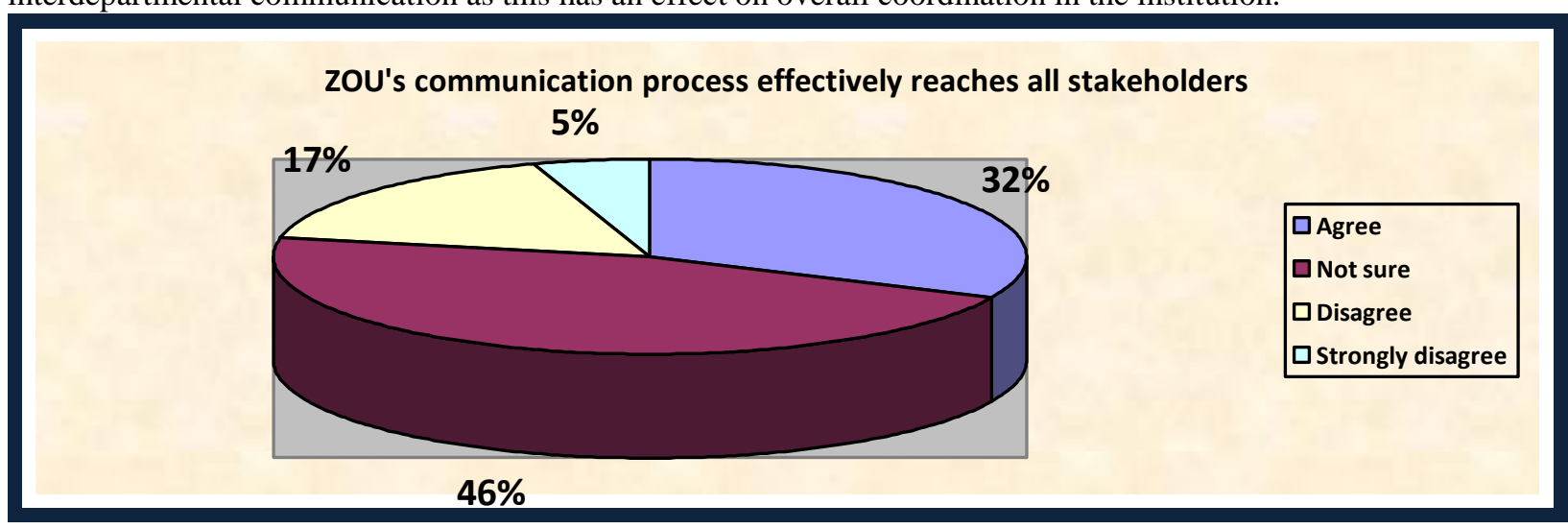

The study further reveals that the ZOU communication process does not effectively reach all key stakeholders. Only $32 \%$ of respondents believed that the ZOU communication process effectively reached all stakeholders. $68 \%$ of respondents were not in agreement with this position.

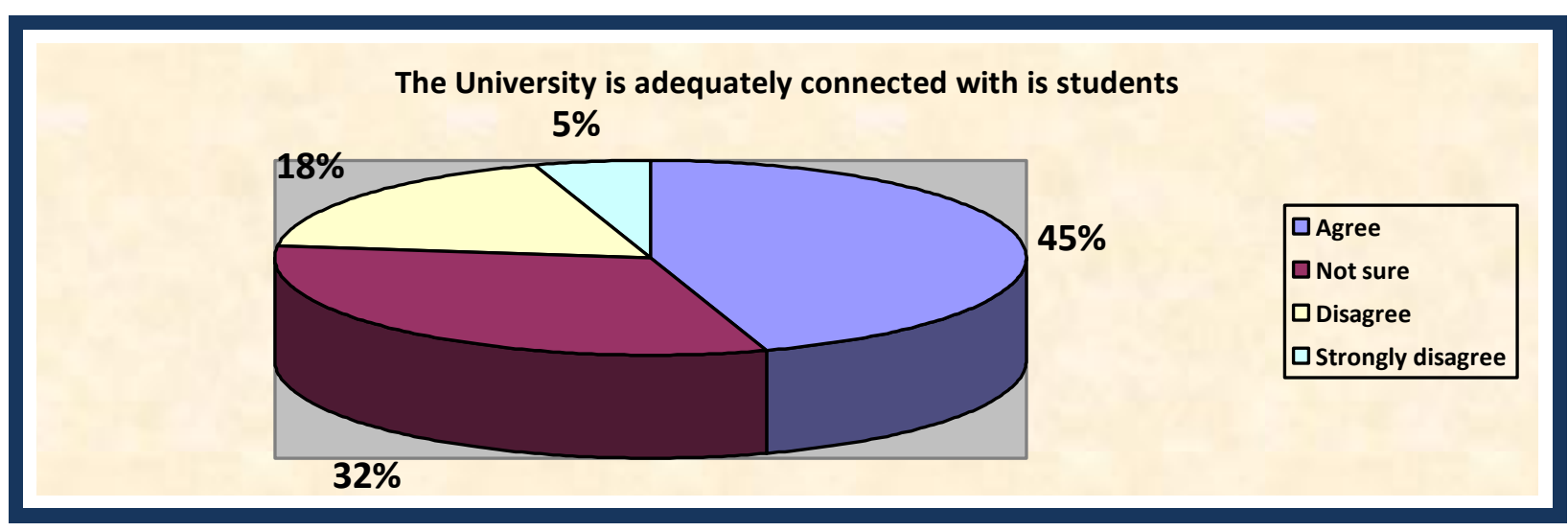


The study reveals that the University is not adequately connected with its customers. Only $45 \%$ of ZOU middle managers believed that the University was adequately connected with its customers.

\section{Decision making}

ZOU middle management is not convinced that they are taken seriously in decision making. Only $42 \%$ of respondents agreed that middle management was taken seriously by senior management in decision making. $58 \%$ were either not sure or disagreed as shown on the pie chart below.

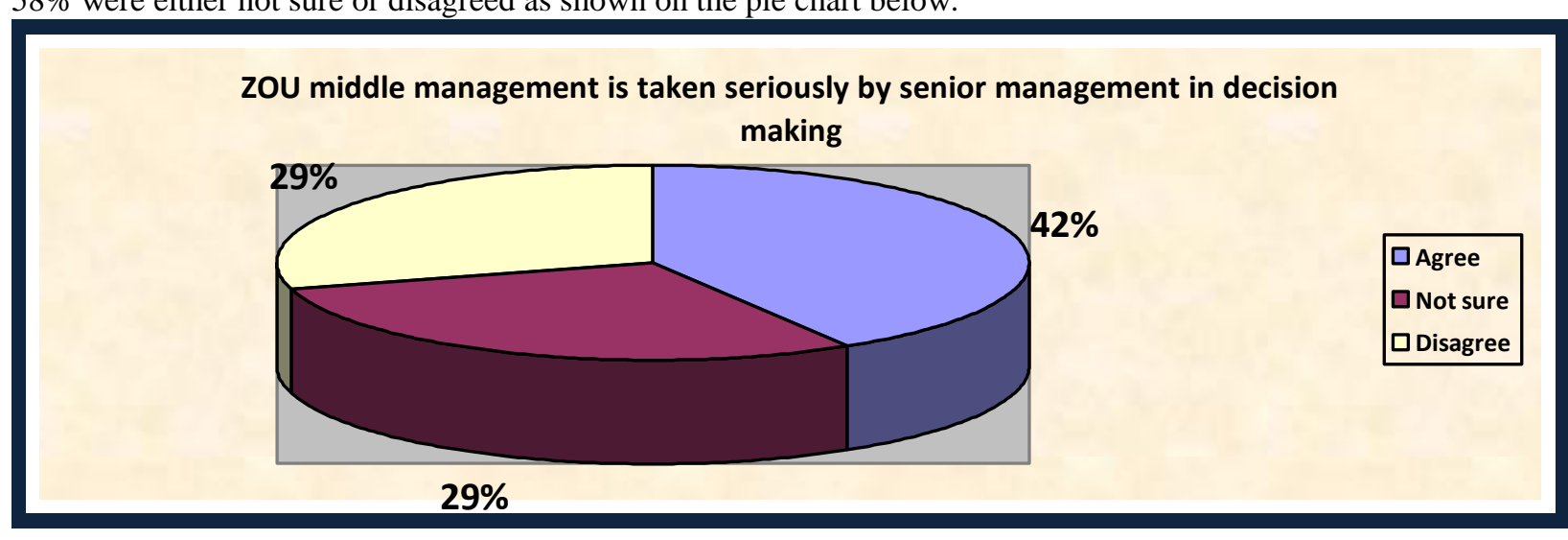

\section{a. Performance evaluation}

The study indicates that the University has instituted reliable performance measures to monitor individual performances. This is supported by $64 \%$ of respondents who agreed that the University had instituted reliable performance measures to monitor individual performances. $36 \%$ of respondents however were not in agreement with this position.

Respondents were divided on the link between performance evaluation and career advancement. 55\% of respondents indicated that the ability to deliver on performance commitments strongly influences career advancement at ZOU. $45 \%$ of respondents were either not sure or disagreed.

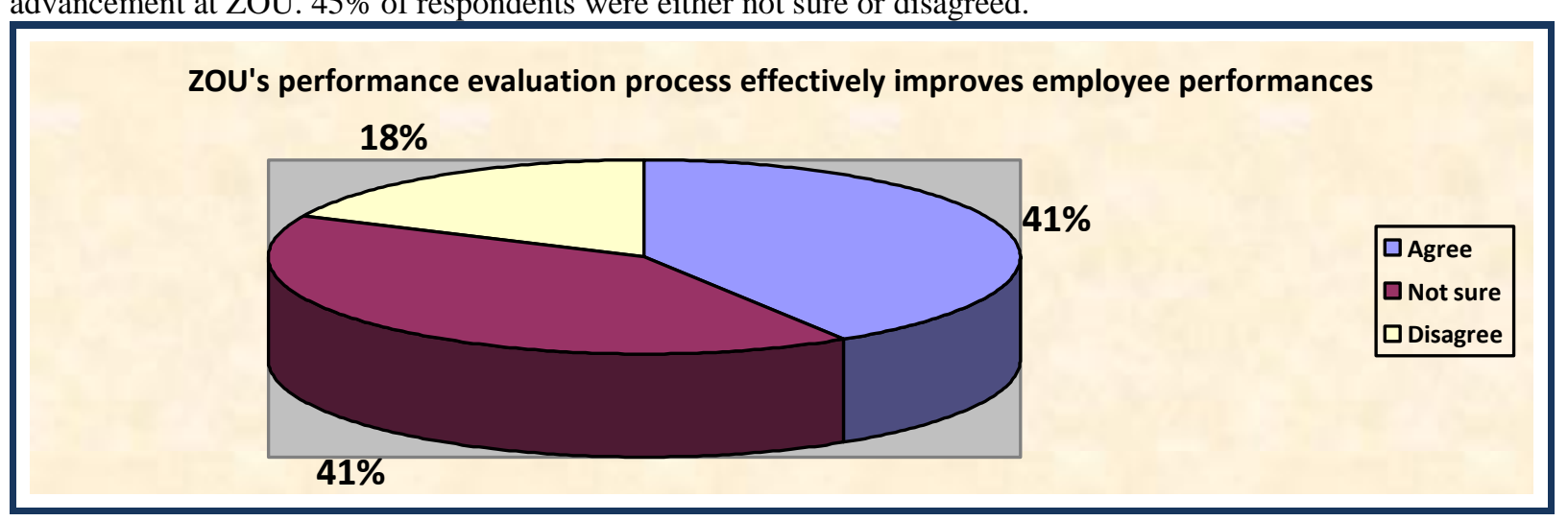

It cannot be conclusively stated that the University's performance evaluation process is serving its purpose in improving individual employee performance. 59\% of respondents were either not sure or disagreed as to whether the University's performance evaluation process was serving its purpose in improving performances. $41 \%$ of respondents however indicated that the performance evaluation process was effectively improving employee performances.

\section{Adaptation to change}

The long term survival of the University depends on its ability to respond effectively to environmental changes. This study revealed that the Zimbabwe Open University is effectively adapting to changes, new challenges, opportunities and threats in the environment. This is reflected by the $63 \%$ of respondents who agreed with this observation. 


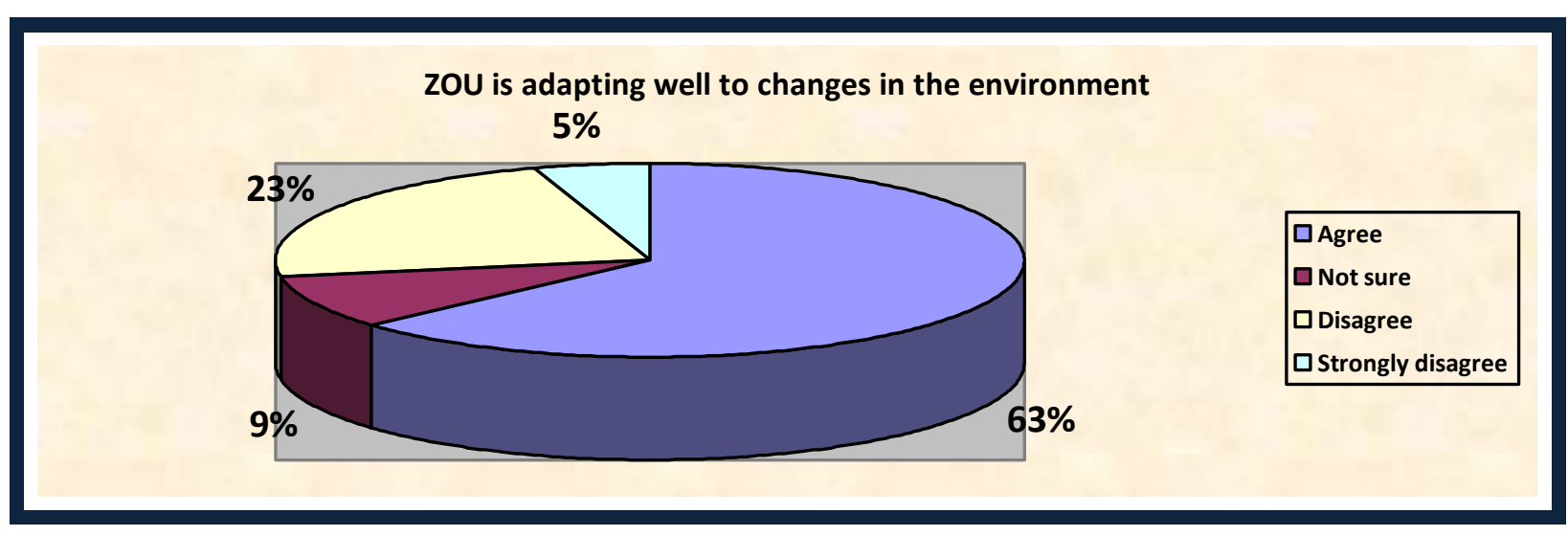

\section{Conclusions}

The Zimbabwe Open University middle management believes that the institution is on course to achieve its goals though there are several challenges that need to be addressed. The goals have been accepted in the institution and most ZOU employees including management are committed to the achievement of the University's goals.

The institution's middle management endorses the strategies and plans that have been developed and implemented in the institution by its leadership. The plans and strategies are said to be relevant to the challenges, opportunities and threats faced by the institution. Middle management thus has confidence in the capability and capacity of the University's leadership.

Although middle management has credited the University's leadership for the conception of relevant strategies and plans to achieve goals, the effectiveness of these initiatives is said to be hampered by limited resource availability.

Though middle management believes that the University's senior management is committed to resource mobilization, they are skeptical about the effectiveness of the manner in which resource mobilization initiatives are conducted. Effective resource mobilization initiatives are therefore required to enable the University to achieve its goals.

The work environment at ZOU is overall not very satisfactory to middle management though employees are regarded as motivated and committed to their work. Employee tardiness and absenteeism have been observed but are not highly prevalent in the institution. Middle management however regard employee turnover as a threat that should be urgently addressed.

Performance evaluation is carried out effectively and reliably in the institution. It is however middle management's view that the results of performance evaluation are not effectively improving employee performances. This could be because performance evaluation results have not been used in structuring the compensation strategy of the University.

The University's values have been communicated to employees but have not been adequately adopted. There is thus a mismatch between the institution's values and the employees' values. This could be due to communication ineffectiveness within the institution.

Middle management believes that feedback between management and employees is poor. They also believe that the University is not effectively connected with its students thus feedback from the market is not effectively conveyed.

It is the perception of middle management that they are not taken seriously in decision making by senior management. Feedback from middle management on student needs and market information is not responded to urgently by senior management therefore some of the decisions made by the University's leadership may be illinformed.

It can be concluded from the findings of this study that the Zimbabwe Open University is effective in conceiving strategies to achieve its goals. The University has capable leaders who are committed to achieving the institution's goals. ZOU middle managers were not sure of the culture of the University. 
Realization of the institution's goals however is hampered by insufficient resources. The resource mobilization initiatives have not been able to complement other facets of the University's drive towards achievement of goals. The university also lacks a clear framework to facilitate communication of feedback between leadership and employees in responding to market changes.

\section{Recommendations}

The study revealed that, the Zimbabwe Open University middle management believed that, the University has the right structure, strategies, leadership, motivated workforce and other necessary requirements to achieve its goals. There are however several issues that need to be addressed. The study thus recommends the following;

- The University need to revitalize its resource mobilization strategies

- Important decisions made at senior management should be made in consultation with middle management

- There is need for a clear feedback mechanism to facilitate communication of market related feedback between ZOU employees, middle management and senior management.

- The University should establish a mechanism to use results of employee performance appraisal in its compensation package. The ZOU allowance is a good platform to institute this performance related compensation strategy.

- To improve connectivity with its students, the University should take advantage of technology and actively participate on social networks.

- Further research be carried out on corporate effectiveness of the Zimbabwe Open University so that University maintains its leading position in Higher Education.

It is hoped that the implementation of the above recommendations would enhance the institution's ability to operate effectively and achieve its goals through increased participation of middle management and other ZOU employees.

\section{Books}

\section{References}

[1]. Ashkenas, R., D. Ulrich, T. Jick, and S. Kerr. 1995. The Boundaryless Organization. San Francisco, CA: Jossey-Bass

[2]. Buckley, Walter. 1967. Sociology and Modern Systems Theory. Englewood Cliffs, NJ: Prentice Hall.

[3]. Christensen, C. M. and M. Overdorf. 2000. Meeting the Challenge of Disruptive Change. Harvard Business Review 78(2):66-78.

[4]. Dooley, Kevin. 1997. A Complex Adaptive Systems Model of Organizational Change.

[5]. Galbraith, Jay R. 1995. Designing Organizations: An Executive Briefing on Strategy, Structure and Process. San Francisco: JosseyBass Publishers.

[6]. Hamel, Gary. 1996. Strategy as Revolution. Harvard Business Review (July-August):69-82.

[7]. Kotter, John P. 1996. Leading Change. Boston: Harvard Business School Press.

[8]. Lawler III., E.E., S.A. Mohrman, and G. Benson. 2001. Organizing for High Performance.

[9]. Employee Involvement, TQM, Reengineering, and Knowledge Management in the Fortune 1000: The CEO Report. San Francisco: Jossey-Bass Publishers.

[10]. Lawrence, Paul R., and Jay W. Lorsch. 1967. Organization and Environment: Managing Differentiation and Integration. Boston, MA: Harvard University. 